\title{
Investigating factors influencing decision-makers' intention to adopt Green IT in Malaysian manufacturing industry
}

\begin{abstract}
Green IT has attracted policy makers and IT managers within organizations to use IT resources in cost-effective and energy-efficient ways. Investigating the factors that influence decision-makers' intention towards the adoption of Green IT is important in the development of strategies that promote the organizations to use Green IT. Therefore, the objective of this study stands to understand potential factors that drive decisions makers in Malaysian manufacturing sector to adopt Green IT. This research accordingly developed a model by integrating two theoretical models, Theory of Planned Behavior and Norm Activation Theory, to explore individual factors that influence decision' makers in manufacturing sector in Malaysia to adopt Green IT via the mediation of personal norms. Accordingly, to determine predictive factors that influence managerial intention toward Green IT adoption, the researchers conducted a comprehensive literature review. The data was collected from 183 decision-makers from Malaysian manufacturing sector and analyzed by Structural Equation Modelling. This research provides important preliminary insights in understanding the most significant factors that determined managerial intention towards Green IT adoption. The model of Green IT adoption explained factors which encourages individual decisionmakers in the Malaysian organizations to adopt Green IT initiatives for environment sustainability.
\end{abstract}

Keywords: Manufacturing sector decision-makers perspectives; Norm activation theory; Theory of planned behaviour; Green IS; Green IT 